Journal of Animal and Veterinary Advances 11 (14): 2465-2468, 2012

ISSN: $1680-5593$

(C) Medwell Journals, 2012

\title{
Genomic Analysis of One Chinese H1N1 Swine Influenza Virus Strain from Healthy Pig Remaining Different Virulence Determinants
}

\author{
${ }^{1} \mathrm{Xu}$ Cong, ${ }^{1} \mathrm{Xue}$ Chun-Yi, ${ }^{1} \mathrm{Lv}$ Li-Shan, ${ }^{1} \mathrm{Li}$ Xiao-Ming, ${ }^{2}$ Shu Ding-Ming, \\ ${ }^{3}$ Lin Zhi-Xiong and ${ }^{1} \mathrm{Cao}$ Yong-Chang \\ ${ }^{1}$ State Key Laboratory of Biocontrol, College of Life Sciences, \\ Sun Yat-Sen University, 510006 Guangzhou, China \\ ${ }^{2}$ State Key Laboratory of Livestock and Poultry Breeding, \\ Guangdong Academy of Agricultural Sciences, Institute of Animal Science, \\ 510640 Guangzhou, P.R. China \\ ${ }^{3}$ Technical Center, Guangdong Entry-Exit Inspection and Quarantine Bureau, \\ 510623 Guangzhou, P.R. China
}

\begin{abstract}
The outbreak of Mexico flu pandemic in the Spring of 2009 has arisen the public attention to swine H1N1 influenza virus because H1N1 influenza virus did not bring a large-scale outbreak in human after causing 1918 Spain flu pandemic. Researchers isolated one swine influenza virus strain A/swine/Guangdong/103/2002 (H1N1) from healthy pig in South China and sequenced its full-length genome. BLASTn analysis showed that all segments of the isolate had the above $99 \%$ similarities with $\mathrm{A} / \mathrm{swine} /$ Shanghai $/ 1 / 2005$, A/swine/Shanghai/2/2005 and A/swine/Shanghai/3/2005 from the severe outbreak of respiratory disease pigs. Although, these four virus strains have high similarities they showed very different virulence. The H1N1 virus could replicate in pigs and mousse without causing clinical symptoms according to the animal regressive experiments results. None of the amino acid substitutions were reported to contribute in the pathogenicity of human and avian influenza viruses providing the basis for virulence determinants research by means of reverse genetics.
\end{abstract}

Key words: Swine influenza virus, H1N1, pathogenesis, determination of virulence, genetics, China

\section{INTRODUCTION}

Influenza A virus is a single-stranded negative-sense RNA virus in the family of Orthomyxoviridae causing respiratory disease in avian, human and swine. Although, the infection of influenza A viruses are generally restricted by their host ranges swine is considered to be mixing vessels for gene segments reassortment among avian human and swine influenza viruses thus swine might play a significant role in the emergence of new influenza viruses which can cause human influenza pandemics (Scholtissek, 1990; Centers for Disease Control and Prevention (CDC), 2009a, b).

In swine, four influenza A virus subtypes circulating throughout the world are classical swine H1N1, avian-like $\mathrm{H} 1 \mathrm{~N} 2$, reassortant $\mathrm{H} 3 \mathrm{~N} 2$ viruses and various genotype H1N2 viruses (Brown, 2000; Marozin et al., 2002; Qi and Lu, 2006; Songserm et al., 2006). The classical H1N1 swine influenza virus was first isolated from pigs in 1930 and it was the first influenza virus isolated (Shope,
1931). The first isolated classical H1N1 evolved from the 1918 Spain pandemic and since, 1930 its progenies have been isolated from swine populations in many regions of the world. Until 1979, the classical H1N1 swine viruses were replaced by the avian-like H1N1 viruses (Brown, 2000; Marozin et al., 2002). Though H1N1 viruses had been frequently isolated from pigs they did not draw much attention from the public or scientific community until the 2009 Mexico flu pandemic. The H1N1 that caused Mexico flu pandemic was considered to be a quadruple reassortant with two genes from swine influenza viruses normally circulating in Europe and Asia, avian and human influenza viruses (Qi et al., 2009).

Most of influenza viruses display different pathogenicity in hosts. Pathogenicity of influenza viruses is dependent on multiple factors. The research about what factors function in the determination of virulence has important implications for public health and agriculture. According to the previous studies many factors can affect the virulence including the quantity of alkalineamino acids

Corresponding Author: Cao Yong-Chang, State Key Laboratory of Biocontrol, College of Life Sciences, Sun Yat-Sen University, 510006 Guangzhou, China 
near the cleavage site of HA protein (Hatta et al., 2001) the amino acid residues 97, 108, 126, 138, 212 and 217 of HA (Hulse et al., 2004), NA stalk length (Castrucci and Kawaoka, 1993), glycosylation sites in the head (Hulse et al., 2004) and the amino acid residues 42, 92 of NS1(Jiao et al., 2008; Seo et al., 2002) are the most significant.

\section{MATERIALS AND METHODS}

Virus isolation and propagation: In this study, researchers isolated and identified one swine H1N1 influenza virus $\mathrm{A} / \mathrm{swine} /$ Guangdong/103/2002 from a healthy pig in South China. The virus was propagated in 10 days old Specific Pathogenic Free (SPF) chicken embryo. At $48 \mathrm{~h}$ post inoculation, allantoic fluid was collected and stored at $-80^{\circ} \mathrm{C}$.

RNA extraction and RT-PCR: Viral RNA was extracted using TRIzol reagent (Invitrogen, Carlsbad, CA). The first strand cDNA was synthesized using Superscript II Reverse Transcriptase (RT) (Invitrogen, Carlsbad, CA) and random primers. The reverse products were amplified by segment-specific primers. The primer sequences are shown in Table 1.

Genetic sequencing: The PCR products were purified and then cloned into the pMD19-T vector (TaKaRa Biotechnology, Dalian, China). Three clones were chosen and sequenced by Shanghai Sangon Biological Engineering Technology and Services Co., Ltd. (Shanghai, China). The nucleotide sequences of $\mathrm{A} /$ swine/Guangdong/103/2002 are available in GenBank accession numbers GQ422382-GQ422389.
Animal regression experiment and PCR detection: The pathogenicity of $\mathrm{A} /$ swine/Guangdong/103/2002 was detected in influenza viruses free mousse by animal regression experiment. Viruses affected mousse through nasal cavity.

Mouse were divided into two groups separately, control group and experiment group. After inoculation, physiological indices were recorded every $24 \mathrm{~h}$. Meanwhile, samples from lungs, spleen, kidney and bowel were detected by PCR. The primer sequences are HA-F: 5'AGCCTTAACGGGATAGCTCCCCTAC-3', HA-R: 5'CTTTGTTATCCACAGCAAATTCCGA-3'.

\section{RESULTS AND DISCUSSION}

The BLASTn anlysis: The BLASTn analysis of eight gene segments of A/swine/Guangdong/103/2002 revealed all gene segments had $>99 \%$ similarities with A/swine/Shanghai/1/2005, A/swine/Shanghai/2/2005 and A/swine/Shanghai/3/2005 (A/swine/Shanghai/1, 2, 3/2005) which were isolated from the lung sample of dead pigs (Qi et al., 2009). It is fascinating that influenza virus strains have much similarities regarding gene segments but diverse in pathogenicity in pigs. In this research, we compare protein sequences of the strain with 3 strains isolated from Shanghai. The different amino acids residues are shown in Table 2.

There are 18 different amino acid residues between A/swine/Guangdong/103/2002 and A/swine/Shanghai/1/ 2005. PB2, NS1 and NS2 amino acid sequences are 100\% identical and the comparison of $\mathrm{PB} 1$ protein showed one different residue. $\mathrm{PA}, \mathrm{HA}, \mathrm{NP}, \mathrm{NA}, \mathrm{M} 1$ and $\mathrm{M} 2$ showed 2, 5, 6, 2, 2 and 1 different residues, respectively. About 14 amino acid residues are different between

Table 1: H1N1 segment-specific primer sequence

\begin{tabular}{|c|c|c|c|}
\hline Genes & Primer sequences $\left(5^{\prime}-3^{\prime}\right)$ & Length of PCR product (bp) & Temperature $\left({ }^{\circ} \mathrm{C}\right)$ \\
\hline \multirow[t]{2}{*}{$P B I$} & Upper: AGC G/A AAAGCAGGCAAACCATTTG & 2341 & 56 \\
\hline & Lower: AGTAGAAACA AGGCATTTTTTCATG & & \\
\hline \multirow[t]{2}{*}{$P B 2$} & Upper: AGC G/A AAAGCAGGTCAAATATATTC & 2341 & 56 \\
\hline & Lower: AGTAGAAACAAGGTCGTTTTTAAAC & & \\
\hline \multirow[t]{2}{*}{$P A$} & Upper: AGC G/A AAAGCAGGTACTGATCC & 2233 & 56 \\
\hline & Lower: AGTAGAAACAAGGTACTTTTTTGGAC & & \\
\hline \multirow[t]{2}{*}{$H A$} & Upper: AGCA A/T AAGCAGGGGAA AATCAAATC & 1777 & 55 \\
\hline & Lower: AGTAGAAACAAGGGTGTTTTTCCATAC & & \\
\hline \multirow[t]{2}{*}{$N A$} & Upper: AGC A AAAGCAGGAGTTT AAAATGAATC & 1463 & 55 \\
\hline & Lower: AGTAGAAACAAGGAGTTTTTTTTCAACG & & \\
\hline \multirow[t]{2}{*}{$N P$} & Upper: AGCA AAAGCAGGGTA A/G ATAATCACTC & 1565 & 55 \\
\hline & Lower: AGTAGAAACAAGGGTATTTTTCATTAATTG & & \\
\hline \multirow[t]{2}{*}{$M$} & Upper: AGCA AAAGCAGGTAGATATTG AAAG & 1027 & 55 \\
\hline & Lower: AGTAGAAACAAGGTAGTTTTTTACTC & & \\
\hline \multirow[t]{2}{*}{$N S$} & Upper: AGC AAAAGCAGGGTGACAAA A/T AC & 890 & 55 \\
\hline & Lower: AGTAGAAACAAGGGTGTTTTTTAGTAC & & \\
\hline
\end{tabular}

/: Means degenerate base 
Table 2: The different amino acid residues between $\mathrm{A} / \mathrm{swine} / \mathrm{Guangdong} /$ $103 / 2002$ with $A /$ swine/Shanghai/ $1,2,3 / 2005$

\begin{tabular}{|c|c|c|c|c|c|}
\hline Protein & $\begin{array}{l}\text { Amino } \\
\text { acids } \\
\text { sites } \\
\end{array}$ & $\begin{array}{l}\text { A/swine/ } \\
\text { Guangdong/ } \\
103 / 2002 \\
\end{array}$ & $\begin{array}{l}\text { A/swine } \\
\text { Shanghai/ } \\
1 / 2005\end{array}$ & $\begin{array}{l}\text { A/swine/ } \\
\text { Shanghai/ } \\
2 / 2005\end{array}$ & $\begin{array}{l}\text { A/swine/ } \\
\text { Shanghai } \\
\text { /3/2005 }\end{array}$ \\
\hline PB1 & 6 & $\mathrm{~T}$ & A & - & - \\
\hline \multirow[t]{7}{*}{ PA } & 105 & $\mathrm{Y}$ & - & $\mathrm{H}$ & $\mathrm{H}$ \\
\hline & 378 & K & - & $\mathrm{R}$ & $\mathrm{R}$ \\
\hline & 428 & I & - & G & G \\
\hline & 455 & A & $\mathrm{S}$ & - & - \\
\hline & 470 & $\mathrm{~L}$ & $\mathrm{P}$ & - & - \\
\hline & 519 & $\mathrm{~N}$ & - & $\mathrm{D}$ & D \\
\hline & 645 & V & - & I & I \\
\hline \multirow[t]{6}{*}{$\mathrm{HA}$} & 7 & $\mathrm{~F}$ & V & - & - \\
\hline & 14 & $\mathrm{~T}$ & A & - & - \\
\hline & 16 & $\mathrm{~N}$ & K & - & - \\
\hline & 241 & $\mathrm{~T}$ & - & - & A \\
\hline & 550 & I & V & - & - \\
\hline & 565 & $\mathrm{C}$ & $\mathrm{Y}$ & - & - \\
\hline \multirow[t]{11}{*}{$\mathrm{NP}$} & 81 & $\mathrm{E}$ & - & K & $\mathrm{K}$ \\
\hline & 101 & D & $\mathrm{N}$ & $\mathrm{N}$ & $\mathrm{N}$ \\
\hline & 162 & $\mathrm{R}$ & - & K & $\mathrm{K}$ \\
\hline & 166 & $\mathrm{~L}$ & - & $\mathrm{Q}$ & Q \\
\hline & 190 & V & - & A & A \\
\hline & 201 & I & V & - & - \\
\hline & 306 & I & - & I & I \\
\hline & 307 & $\mathrm{~L}$ & $\mathrm{P}$ & - & - \\
\hline & 341 & $\mathrm{~L}$ & I & - & - \\
\hline & 398 & Q & K & - & - \\
\hline & 471 & A & $\mathrm{T}$ & - & - \\
\hline \multirow[t]{2}{*}{ NA } & 3 & $\mathrm{P}$ & $\mathrm{T}$ & $\mathrm{T}$ & - \\
\hline & 188 & V & M & M & - \\
\hline \multirow[t]{2}{*}{ M1 } & 10 & del & $\mathrm{P}$ & P & $\mathrm{P}$ \\
\hline & 34 & I & $\mathrm{T}$ & $\mathrm{T}$ & - \\
\hline \multirow[t]{3}{*}{ M2 } & 30 & D & - & - & $\mathrm{N}$ \\
\hline & 35 & K & $\mathrm{R}$ & $\mathrm{R}$ & - \\
\hline & 47 & K & - & - & $\mathrm{T}$ \\
\hline NS1 & 14 & M & - & - & $\mathrm{K}$ \\
\hline NS2 & 171 & D & - & - & E \\
\hline
\end{tabular}

del means deletion: -: Means amino acid as the same as $\mathrm{A} / \mathrm{swine} /$ Guangdong $/ 103 / 2002$

A/swine/Guangdong/103/2002 and A/swine/ Shanghai/2/2005 which locate on protein PA, NP, NA, M1 and M2. Researchers also, discovered 11 amino acid residues changed in $\mathrm{A} / \mathrm{swine} /$ Guangdong/103/2002 and A/swine/Shanghai/3/2005. These residues are HA 241, NP 81, 101, 162, 166 and 196, M1 10, M2 30 and 47, NS1 14 and NS2 171. Researhers notice that M1 protein has one missing amino acid at position 10 compared to the 3 strains.

Result of animal regression experiment: The PCR detection results (Fig. 1) showed that $\mathrm{H} 1 \mathrm{~N} 1$ could replicate in mouse but this strain did not cause clinical symptoms. Researchers consider that A/swine/ Guangdong/103/ 2002 could infect mouse but this virus has no pathogenic. This result keeps identical with the source of the virus which isolated from healthy pig.

Although, pigs are considered as influenza virus genes mixing vessel, swine influenza viruses did not getenough attention until 2009 Mexico flu happened.

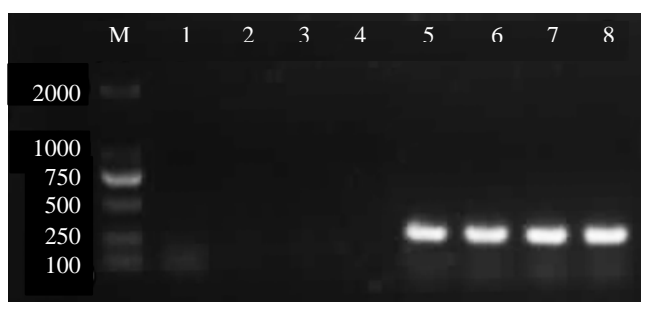

Fig. 1: Polymerase Chain Reaction (PCR) analysis of samples from animal regressive experiments. MW: DL2000 DNA Marker; Lane 1-4: PCR results of samples from control group, Lane 1-4 are lungs, spleen, kidney and bowel of mouse, respectively; Lane 5-8: PCR results of samples from experiment group, Lane 5-8 are lungs, spleen, kidney and bowel of mouse, respectively.

Most studies about determination of influenza virus pathogenicity focused on the human influenza viruses and avian influenza viruses.

\section{CONCLUSION}

According to results of comparing protein sequences of $\mathrm{A} /$ swine/Guangdong/103/2002 to A/swine/Shanghai/1, 2, 3/2005, researchers found some amino acid substitutions. But none of them were reported to contribute in the pathogenicity of influenza viruses. Considering the total different pathogenicity of $\mathrm{A} /$ swine/Guangdong/103/2002 and A/swine/Shanghai/1, 2, 3/2005 maybe two reasons can explain. Firstly, determinations of pathogenicity of human and avian influenza viruses which revealed by researches are not suit for swine influenza viruses or these factors do not play important role in the pathogenicity of swine influenza viruses. Secondly, there are many factors are not discovered responsible for pathogenicity. We can get information about which amino acids are related to the pathogenicity from this study and reverse genetics can be used as a good tool to confirm it.

\section{ACKNOWLEDGEMENT}

This rsearch was supported by the grants from State Public Industry Scientific Research Programs.

\section{REFERENCES}

Brown, I.H., 2000. The epidemiology and evolution of influenza viruses in pigs. Vet. Microbiol., 74: 29-46. 
Castrucci, M.R. and Y. Kawaoka, 1993. Biologic importance of neuraminidase stalk length in influenza A virus. J. Virol., 67: 759-764.

Centers for Disease Control and Prevention (CDC), 2009a. Swine influenza A (H1N1) infection in two childrenSouthern California, March-April 2009. MMWR Morb. Mortal Wkly. Rep., 58: 400-402.

Centers for Disease Control and Prevention (CDC), 2009b. Update: Swine influenza A H1N1) infectionsCalifornia and Texas, April 2009. MMWR Morb. Mortal Wkly. Rep., 58: 435-437.

Hatta, M., P. Gao, P. Halfmann and Y. Kawaoka, 2001. Molecular basis for high virulence of Hong Kong H5N1 influenza A viruses. Science, 293: 1840-1842.

Hulse, D.J., R.G. Webster, R.J. Russell and D.R. Perez, 2004. Molecular determinants within the surface proteins involved in the pathogenicity of $\mathrm{H} 5 \mathrm{~N} 1$ influenza viruses in chickens. J. Virol., 78: 9954-9964.

Jiao, P., G. Tian, Y. Li, G. Deng and Y. Jiang et al., 2008. A single-amino-acid substitution in the NS1 protein changes the pathogenicity of H5N1 avian influenza viruses in mice. J. Virol., 82: 1146-1154.
Marozin, S., V. Gregory, K. Cameron, M. Bennett and M. Valette et al., 2002. Antigenic and genetic diversity among swine influenza A H1N1 and H1N2 viruses in Europe. J. Gen. Virol., 83: 735-745.

Qi, X. and C.P. Lu, 2006. Genetic characterization of novel reassortant H1N2 influenza $A$ viruses isolated from pigs in southeastern China. Arch Virol., 151: 2289-2299.

Qi, X., B. Pang and C.P. Lu, 2009. Genetic characterization of H1N1 swine influenza A viruses isolated in eastern China. Virus Genes, 39: 193-199.

Scholtissek, C., 1990. Pigs as mixing vessels for the creation of new pandemic influenza A viruses. Med. Principles Pract., 2: 65-71.

Seo, S.H., E. Hoffmann and R.G. Webster, 2002. Lethal H5N1 influenza viruses escape host anti-viral cytokine responses. Nat. Med., 8: 950-954.

Shope, R.E., 1931. Swine influenza: III. Filtration experiments and etiology. J. Exp. Med., 54: 373-385.

Songserm, T., A. Amonsin, R. Jam-On, N. Sae-Heng and N. Meemak et al., 2006. Avian influenza H5N1 in naturally infected domestic cat. Emerg. Infect. Dis., 12: $681-683$ 